\title{
Chronic Currency Crisis Continues
}

THE latest bout of uncertainty about the stability of the international currency system has now been temporarily resolved by yet another adjustment of parities. Next will come more concessions to the United States on the restriction of international trade and a still further complication of the rules that govern the international money market and in particular the still further elaboration of the attempt to distinguish between commercial and capital transactions of the kind now embodied in their purest form in the two-tier system operated by the French. Nobody will expect that the new arrangements will last very long. It has taken just over twelve months for the Smithsonian Agreement to collapse. But the prospects for the future are not especially bright. The restrictions on imports maintained by the Japanese government will no doubt continue, in flagrant violation of the spirit if not the letter of the General Agreement on Tariffs and Trade. The United States will no doubt be edged in the same direction by the uncertainties of the past few weeks. And there is still no sign that the European Community is in a position or even a mood to create the financial institutions without which the concept of a European Community is incomplete.

What is to be done? The first need is that there should be a concerted attack on the Japanese position. The remarkable growth of the Japanese economy in the past few years is entirely a consequence of the way in which the Japanese export trade has flourished and thus of the willingness of countries elsewhere to import Japanese goods freely. During 1972, nations such as the United States and Britain, anxious to reduce the resulting drain on their balance of payments, have attempted to persuade the Japanese government to induce Japanese exporters to adopt voluntary restrictions on their export trade, but this expedient is at once unworkable and less satisfactory than a thorough liberalization of the rules by means of which the government of Japan ensures that it remains in surplus with its trading partners. But since Japan has every interest in being in the international swim, it is surely a simple issue of international diplomacy that there should be a further and rapid liberalization of Japanese trade. Whether the result would be, as the United States would hope, an immediate rectification of the adverse balance of United States trade is however doubtful-what the Administration has to acknowledge is that the effective devaluation of the dollar in 1971 and that now in effect have been brought about by the changed balance of prosperity between the United States and the other advanced countries of the world which has become apparent in the past decade.

Where the European Community is concerned, the immediate need is to develop machinery not merely for forming a common financial policy but for broadening the base within which such a policy is worked out. At the Paris Summit meeting last year, the nine members of the European Community paid lip service to the view that by the end of the present decade there should be a common monetary system, which implies not merely a common unit of currency but the financial institutions needed to back it up and, more important, a measure of permanent agreement on the equitable distribution of resources within the European Community. In other words, before a monetary union is possible, the member countries of the European Community will have had to agree on a common policy for the support of social services, including the arrangements for paying unemployment benefits to those who are out of work. There will have to be a common regional policy and machinery for economic planning at least in the broad sense of determining the steps which need to be taken to ensure an equitable distribution of industry and of jobs within the nine member states.

Currency crises are either calamities or opportunities according to the mood of those who must deal with them. Formidable though the obstacles to economic integration in Europe may be, one of the disappointments of the past week's negotiations is the apparent lack of an explicit recognition that the edge might be taken off the problem of currency instability by accelerating the timetable provisionally agreed in Paris for economic union. On the face of things, it would have done no harm at all if $\mathrm{Mr}$ Anthony Barber, the British representative at last week's Paris meeting, had advocated that the timetable for economic union should be advanced to, say, July 1974. Although there are formidable issues to be settled, what needs to be done is clear enough and the European Community has in the past made progress chiefly by setting itself apparently impossible timetables and then staying up all night to meet them. And in the present situation, anyway, the whole concept of the European Community will be incomplete until these radical issues are decided. Indeed, the arrangements which the community is trying to force on its members for the regulation of currency transactions themselves contain the seeds of further instability. Currencies are meant to move only narrowly against each other, and the British government has promised that the floating pound will eventually be fixed. But how can such a system survive the inevitable imbalances of trade among the members of the European Community if there is no mechanism for making sure that countries which run a deficit on their trading balance are somehow helped to make up the difference? It follows that the members of the European Community should hurry to settle their internal arrangements for exchanging currencies in case they find they have built into their internal arrangements the kind of instability which has now emerged internationally. It is unthinkable that the present system can survive until 1980 and the sooner European governments acknowledge that the better. 